\title{
Imagen fotográfica y memorial cultural. El caso de los judíos en la prensa gráfica de la primera mitad del siglo $\mathrm{XX}$
}

\author{
Antonio B. EsPINOSA-RAMÍREZ \\ abespinosa@ugr.es \\ Universidad de Granada \\ Antonio A. Ruíz-RodríGuez \\ aangel@ugr.es \\ Universidad de Granada
}

Recibido: 31 de julio de 2014

Aceptado: 9 de diciembre de 2014

\begin{abstract}
Resumen
La fotografía juega un papel decisivo en la formación del imaginario colectivo y la memoria cultural. A través de las fotografías publicadas en la prensa gráfica se analizan los mecanismos de connotación de las imágenes para que estas puedan ser interpretadas por los lectores en claves de memoria cultural aplicada a un grupo humano concreto: lo judíos. Se analizan los mecanismos que visualizan y definen al grupo y el de los estereotipos que los definen en la memoria cultural occidental.
\end{abstract}

Palabras clave: fotografía, análisis de imágenes, Prensa gráfica, Memoria cultural, judíos.

Photographic Image and cultural memory. The case of the Jews in the graphic press of the first half of the twentieth century

\begin{abstract}
Photography plays a decisive role in the formation of the collective imaginary and cultural memory. Through the photographs published in the graphic press, the mechanisms of connotation of the images so that they can be interpreted by the readers in cultural memory key applied to a specific group of people, the Jews, are analyzed. The mechanisms that visualize and defining the group, and the stereotypes that define them in Western cultural memory are analyzed.

Keywords: Photography, Graphic press, Cultural Memory, Jews, Image analisys.

\section{Referencia normalizada}

ESPINOSA-RAMÍREZ, Antonio B. y RUÍZ-RODRÍGUEZ, Antonio A.: "Imagen fotográfica y memorial cultural. El caso de los judíos en la prensa gráfica de la primera mitad del siglo XX". Estudios sobre el Mensaje Periodístico. Vol. 21, Núm. 1 (enero-junio), págs.: 105-113. Madrid, Servicio de Publicaciones de la Universidad Complutense.
\end{abstract}

Sumario: 1. Introducción: objetivos, método y fuentes. 2. Marco teórico. 3. Análisis; 3.1. Visión y mensaje. 4. Conclusiones. 5. Referencias bibliográficas.

\section{Introducción: objetivos, método y fuentes}

Las revistas gráficas surgen en España a finales del siglo XIX y tienen su época dorada durante las primeras décadas del siglo XX. La incorporación de la fotografía sustituye al grabado, presente hasta entonces en las revistas ilustradas. Mientras el grabado representa una interpretación, la fotografía, aparentemente, pretende ser un fiel reflejo de la realidad, un analogón (Barthes, 1986) y como tal es percibido por el lector. Esta característica la convierte en instrumento de transmisión y construcción de la memoria, de elaboración de una Imagen y de fijación de identidades. 
Nuestro objetivo es analizar cómo la fotografía presenta a un grupo humano determinado, los judíos (y lo judío como conjunto de atributos que se le adjudican a dicho grupo), y establecer las relaciones existentes entre la fotografía, sus elementos connotativos y la memoria cultural.

Para desarrollar este trabajo hemos analizado las fotografías en las que aparecen judíos, y aquellos componentes de la imagen que caracterizan la visión que de ellos se ofrece a los lectores, en concreto, los elementos y características de tipo visual que remiten a claves culturales que han definido, y vienen definiendo, a los judíos a lo largo de la historia por parte de la cultura occidental.

La investigación la centramos en un espacio temporal: desde el nacimiento de las primeras revistas gráficas hasta la creación del nuevo estado de Israel en mayo de 1948. La época seleccionado (además de coincidir con el nacimiento y eclosión de las revistas gráficas) coincide con acontecimientos históricos en el que de alguna manera el papel de los judíos o su presencia es evidente: caso Dreyfus y surgimiento del antisemitismo moderno, intervenciones españolas en Marruecos y creación del Protectorado, Gran Guerra, Revolución Rusa, vanguardias culturales, aparición del nacismo y el fascismo, inicio del proyecto sionista, República española y Guerra Civil, Guerra Mundial, Holocausto y proceso descolonizador.

Las fuentes utilizadas han sido una selección de las principales revistas (generalistas) gráficas del periodo: Blanco y Negro, Nuevo Mundo, Mundo Gráfico, La Esfera, Estampa, Crónica y Mundo. A pesar de no existir una sola revista que abarque el periodo de tiempo seleccionado, si lo hacen entre todas, incluso coincidiendo algunas en el tiempo y reflejan la pluralidad ideológica y empresarial existente.

\section{Marco teórico}

El acercamiento al concepto de Memoria se puede realizar desde distintas perspectivas que van a fluctuar dependiendo de quién las utilice (Matas Morell, 2010:79) como memoria social, colectiva, cultural, histórica, local, oficial, etc. Partiendo de la idea de memoria individual, que es la que recuerda o reinterpreta los acontecimientos -en muchos casos realizando un ejercicio sobre el pasado para proyectarlo sobre el presente, nos vamos a centrar en el concepto de memoria colectiva o social y memoria cultural.

Memoria colectiva o memoria social, es la que da forma a una sociedad y la define mediante mecanismos en los que juegan un alto papel las creencias, los valores y las normas culturales (Cattell; Climo, 2002). Es por tanto, una memoria que incluye temas tan diversos como moral, poder, lecturas mayoritarias hegemónicas y oposiciones minoritarias, etc. Es un producto ideológico. Esta característica, que posibilita que la memoria colectiva pueda ser provisional, inventada y reinventada, permite también que pueda ser persistente y acumulativa de manera que algunos aspectos del pasado, ya sean estos ciertos o inventados, sean resistentes a la revisión, y persistan por la inercia y la fuerza de los hábitos.

La memoria se construye y reconstruye mediante una dialéctica de recuerdo y olvido, y por la utilización de objetos, estereotipos, cuadros semánticos interpretativos, signos, etc, que se denominan memory repertoires, concebidos como elementos de ligazón en algunas sociedades y que dotan de significado a la memoria social. Estos mecanismos permiten crear conciencia de grupo, son los que sustentan la memoria 
cultural, que se coloca en un plano más amplio que la propia memoria colectiva o social aunque está ligado a esta.

En las sociedades escritas y más con la utilización de la imagen, la cristalización y la transmisión de la memoria se vale de textos e imágenes para interpretar, reinterpretar, simbolizar y resimbolizar, abriendo el camino a la creación de etereotipos. Es la idea de Halbwachs (2004) de que la memoria, como reconstrucción del pasado, necesita enmarcarse en un contexto y cristalizarse a través de textos e imágenes. Esto supone la existencia de una imagen mental de la que extraemos el significado porque teóricamente es la que más se aproxima a lo "recordado", y que viene a actuar como descriptor/interpretador (Raposo Quintana, 2009:100). Conectada con el pasado, perviviendo en el presente y configurando el futuro, este imaginario es denominado también memoria estética (Gaona Pisonero; Torregrosa Carmona, 2013:199). Los estereotipos sirven como imágenes sociales que concentran toda una memoria y una cultura que pude de esta forma ser recordada e identificada con facilidad. Son una disputa entre lo natural y lo construido, y se presentan disueltos, sin apenas dejar rastros de su presencia, como criptogramas sociales tras los que se esconden un miríada de valores, (González Galiana, 1999: 101). Baer (2005: 256), parafraseando a Foucalt, escrbe de las tecnologías de la memoria, incluyendo entre ellas a los medios tecnológicos, las prácticas sociales y culturales que la registran y documentan, y lo que denomina monumentación del conocimiento del pasado que se transforma en memoria.

La fotografía juega un papel clave en la construcción del imaginario: la imagen fotográfica siempre esta modulada por el cincel ideológico, por los discursos hegemónicos, por los mecanismos de poder y por su capacidad de evocar contextos (Grau Rebollo, 2002) de manera que se convierte en un mecanismo de creación de alteridad en estrecha relación con el imaginario: es un producto cultural que incide de manera clara sobre la re/construcción de la memoria, la fija, modifica, recrea, interpreta, resimboliza, etc. Ese imaginario social es por tanto representación social, y tiene como función regula y orienta las acciones de los miembros de una sociedad y una cultura, y determina las maneras de sentir, desear y pensar (Fressard, 2006).

Estos imaginarios, generados por los espacios de poder son difundidos por los medios de comunicación audiovisual en todas sus tipologías, convirtiéndose, en representaciones que modelan, participan, perpetúan y modifican la memoria social. Esto hace que la fotografía no sea sólo un objeto histórico, sino un agente articulador de la historia. La fotografía de prensa se articula como un mecanismo con su propio mensaje, independientemente del texto al que pueda acompañar, tiene su propia autonomía comunicativa, su propia narración visual que va más allá de su mero valor de refuerzo del mensaje textual que la reduce a una vertiente probatoria de lo escrito como han llegado a afirmar algunos autores (Irala Hortal, 2011). La imagen, y por tanto la fotografía, funciona como memoria estética, que es una subcategoría de la memoria colectiva en la que está cimentada en el pasado, alimenta el presente y diseña el futuro (Gaona Pisonero; Torregrosa Carmona, 2013: 199).

El imaginario es también una imagen de identidad colectiva que se proyecta sobre la historia (Aguirre, 1977:268) y que se constituye en reconstrucción iconica, cultural y corporal. En el caso de los judíos, esta imagen toma cuerpo desde el siglo XII en portadas de iglesias, retablos, manuscritos, etc hasta la actualidad en los diversos for- 
matos audiovisuales (Molina Figueras, 2007:38). Los judíos cumplen la función del Otro como sujeto histórico colectivo en la memoria cultural. Se les presenta con una naturaleza (física y conductual) distinta y muy definida, dando lugar a una figura histórica, a una imagen simbólica, a una representación que pretende ser expresión de la realidad, pero que no es objetiva, sino fruto de unos intereses de poder anclados en el papel que se les ha adjudicado a lo largo de la historia.

En España, ese papel del Otro ha sido adjudicado por excelencia a los judíos, pero también, en mayor o menor medida, y dependiendo del periodo histórico, lo han asumido los musulmanes (el moro), los ilustrados y liberales en el siglo XIX, y los rojos y masones en el siglo XX, algunas veces incluso a la par, como la publicitada durante la dictadura del general Franco, conspiración judeo-masónica-bolchevique.

El caso judío reúne una particularidad especial que debemos contemplar desde el terreno de la ideología y en contacto con la historia de las mentalidades y la sicología social que analiza el comportamiento de los grupos humanos. La imagen del judío hay que abordarla desde la relación que, como grupo, tienen en la memoria cultura y colectiva de una sociedad hegemónica cristiana. Esta sociedad extrae de un grupo socioecómico heterogéneo, determinados rasgos y características (físicas y sicológicas) propias de determinados individuos de cualquier colectivo y lo hacen extensible a todo el grupo como sea de identidad, construyendo un etereotipo que se ha quedado anclado en el subconsciente de la población. El judío es el representante de la Alteridad negativa en el universo cultural occidental (Semprum, 1986). La imagen del judío histórico está cargada de prejuicios, sospechas y acusaciones que forman lo que conocemos como prejuicio de grupo al proyectar sobre éste características que son consideradas como inmutables.

Estas características, estos argumentos con los que los judíos son señalados y que conforman la representación que de ellos se tiene son de diversa índole, pero dan lugar a dichas representaciones esquemáticas (Caro Baroja, 1978) que han sentado las bases del atijudaísmo español y en buena parte occidental, hasta la llegada del antisemitismo moderno a finales del XIX. Las ideas esquemáticas sobre las que trabaja este estereotipo son:

- Los argumentos de tipo religiosos que parten de la consideración de los judíos como pueblo deicida.

- Los argumentos centrados en aspectos económicos que presentan al judío ligado a la usura y la especulación.

- Las características sicológicas que se les adjudica como la soberbia, la inteligencia peculiar, su propensión a la traición, etc.

- Por último las características físicas que los identifican y representan. Rasgos propios que son extensibles a todo el grupo.

Partiendo del análisis de las 350 imágenes recuperadas en las revistas gráficas seleccionadas, hemos extraído y analizado los argumentos y representaciones de los judíos, y de lo judío (lo que define a los judíos), que se transmiten mediante el mensaje fotográfica durante el periodo estudiado. 


\section{Análisis}

Las siete revistas analizadas: Blanco y Negro, Nuevo Mundo, Mundo Gráfico, La Esfera, Crónica, Estampa y Mundo, han sido seleccionadas por abarcar todo los años sobre los que nos proponíamos enfocar nuestro trabajo (desde la aparición de las revistas gráficas hasta la creación del Estado de Israel) y ser las más generalistas, representativas, de mayor tirada y calidad, y representar a los distintos grupos editoriales españoles de la época. Como hemos visto anteriormente, no hay una sola revista que pueda abarcar todo el tiempo, pero entre todas no dejan ningún año sin cubrir. Las más longevas como Nuevo Mundo y Blanco y Negro, coinciden con el resto durante determinados años, y el periodo posterior a la Guerra Civil ha sido analizado siguiendo a la única revista gráfica de consideración como Mundo que a su vez representaba la posición oficial del régimen. A continuación mostramos un gráfico que representa los años analizados desde la aparición de la primera fotografía hasta el número de 25 de mayo de 1948, una vez declarado el Estado de Israel.

$N^{\circ}$ Imágenes y año

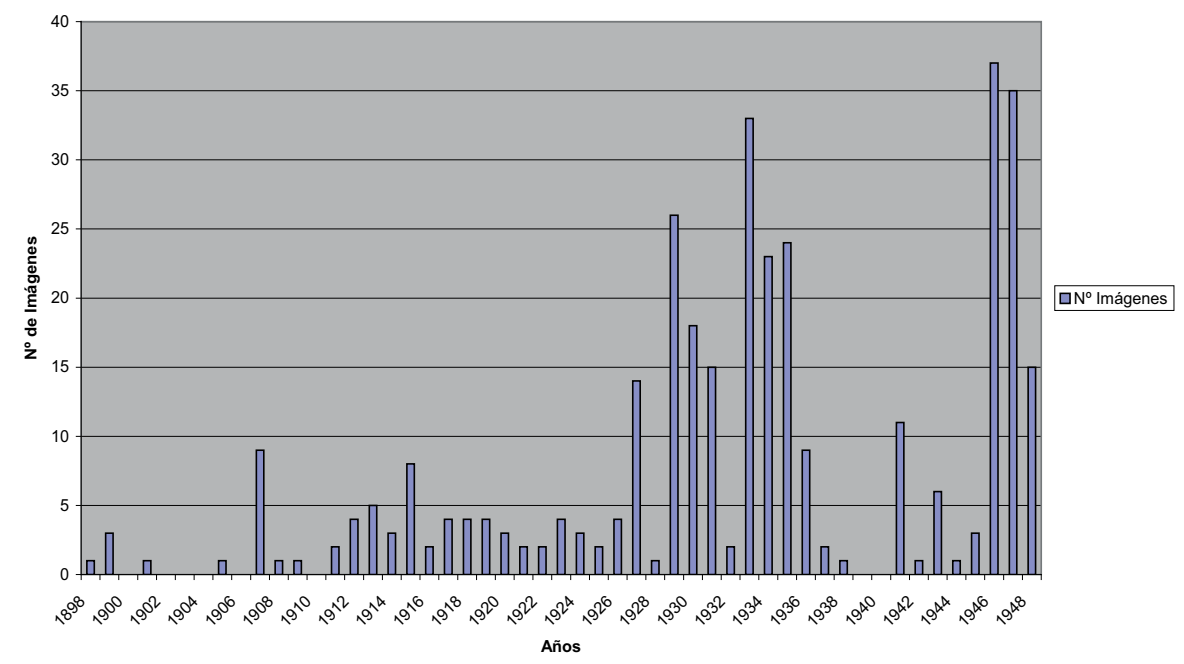

Como podemos observar, se han analizado los números correspondientes a 58 años, desde 1891 (hemos comentado que la primera fotografía es de 1898 en Nuevo Mundo) hasta 1948. En total hemos encontrado y analizado 350 imágenes de la cuales 325 corresponden a fotografías y 25 a otro tipo de ilustraciones como dibujos, comic o reproducciones pictóricas.

Las primeras imágenes vienen a ilustrar informaciones sobre el conocido "Asunto Dreyfus" que en aquellos momentos estaba de actualidad en Francia y en España pero que al contrario que en el caso francés, en las revistas españolas no se le alude como judío, sino como traidor. Una vez analizadas, y tal como se refleja en el gráfico, el mayor despliegue informativo gráfico se produce en 1907 durante la intervención franco-española en Casablanca con abundantes fotografías de los judíos de la ciudad que han sido protegidos por las tropas españolas y francesas ante la revuelta de la po- 
blación local que tradicionalmente los hacía objetivo de sus ataques en tiempo de revueltas. Desde ese año y fundamentalmente a partir de 1912, con la instauración del Protectorado Español de Marruecos ${ }^{1}$, hasta inicios de los años 30 del siglo XX (fundamentalmente durante los años 10 y 20), las imágenes sobre los judíos del Protectorado son habituales en las revistas. Su imagen, como hemos visto se engloba dentro del particular orientalismo español y los estereotipos aplicados a los judíos (EspinosaRamírez, 2013) y (Morales-Lezcano 1988). El descubrimiento de estas juderías marroquíes despierta también un interés por las juderías españolas apareciendo distintos reportajes sobre estas fundamentalmente en la revista La Esfera.

También hay que destacar temáticamente el descubrimiento de Jerusalén y Palestina para Occidente tras la ocupación del territorio por parte de las tropas británicas de Allenby en 1917-18, y el establecimiento del Mandato Británico de Palestina tras el desmembramiento del Imperio Otomano por parte de la Sociedad de Naciones. Los medios reflejan la campaña como una recuperación de lo que consideran Santos Lugares, la tierra de la Biblia y como tal son numerosas las imágenes al respecto. Es en este contexto donde van a aparecer numerosas imágenes de judíos que son redescubiertos como habitantes del lugar. Las fotografías nos suelen presentar a judíos ortodoxos o mendigos pegados a su religiosidad y a su vida en Jerusalén que gira en torno al Kotel (Muro de las lamentaciones). Así mismo, nos vamos a encontrar con las primeras imágenes que sirven para ilustrar informaciones sobre un nuevo movimiento político denominado Sionismo y de las nuevas colonias y ciudades que se están construyendo. Estas imágenes no suelen ir acompañadas de imagen física de esos judíos, son fotografías de lugares como Tel Aviv o de kibutz en el Valle de Jezrael, pero nunca de personas, y cuando estas aparecen responden al tipo judío buscado y que puede ser identificado como tal.

A partir de los años 30 las ilustraciones aumentan considerablemente, son los años donde el periodismo gráfico alcanza su esplendor y aumentan los reportajes temáticos. Estos reportajes se centran en diversos asuntos como: la "conspiración judía" (tan en boga entonces en España y Europa), el sionismo, los refugiados judíos del nazismo, etc. La Guerra civil supone un brusco cambio pues los medios van pasando a manos de grupos políticos centrándose en la contienda hasta su completa desaparición.

Los años cuarenta los hemos analizado a través del único medio gráfico de calidad de entonces, la revista Mundo editada por EFE y versión oficial del régimen. Allí los temas principales se centrarán en la acción española en Marruecos y el conflicto que se desarrolla en el Protectorado británico de Palestina.

1 La Conferencia de Algeciras celebrada en 1906 por las potencias europeas abre la puerta a un protectorado en Maruecos que sería ejercido por Francia y España. Este protectorado se define mediante el Tratado de Fez en 1912 delimitando un protectorado español en el norte y uno francés en el sur. Los incidentes de 1907 (antes de definir los territorios) vienen a sofocar una revuelta producida en Casablanca cuyo origen estaba en el trazado de una vía férrea por parte de una compañía francesa que atravesaba un cementerio musulmán y que degeneró en asaltos sobre la población europea y judía. 


\subsection{Visión y mensaje}

Son varios los mensajes y visiones coincidentes en las distintas revistas que van sucediéndose a lo largo de los años, la principal tiene que ver con la propia identificación física del judío. ¿Cómo identificar a un judío del resto de las personas?: los fotógrafos buscan unas características físicas, unas imágenes estereotipadas identificables en la memoria cultural occidental, que en el caso de los judíos vienen siendo definidas desde la Edad Media (Baer y Zukierman, 2004), que a su vez devienen en actitudes sicológicas (Gilman, 1991) y que definen tanto al individuo como al grupo. Se buscan y representan rasgos característicos como la nariz aguileña, las actitudes son seductoras, astutas o de desconfianza, la piel enfermiza, etc. Otro rasgo característico es la vestimenta, los judíos buscados y fotografiados siempre son religiosos y suelen vestir como tales: los sefardíes con kipá y chilaba, los askenazís (centro europeos) con ropas negras, largas túnicas, sombreros shtreimel o de ala ancha, cubiertos con el manto de oración, etc... y luego los judíos jerosolimitanos o palestinos que siempre suelen ser ultrareligiosos y son fotografiados junto al Muro de los lamentos o en las cercanías. Estas imágenes repetitivas son utilizadas aunque los religiosos sean una minoría dentro de las comunidades judías representadas. Este mecanismo de identificación no puede en cambio ser utilizado cuando el judío fotografiado viste a la manera occidental; en este caso, simplemente se ignora la condición de judío porque no se ajusta al tipo de judío estereotipado y reconocible por el lector y la memoria cultural. Otra coincidencia se produce en las fotografías de grupo, si visten como judíos, el objetivo se acerca, si no es el caso, como el las fotografías de las nuevas comunidades de Palestina, como Tel Aviv, el objetivo se aleja y hace hincapié en el urbanismo.

Otro de los mensajes repetido a través de las fotografías es el del judío como conspirador. En este caso, y debido a la complejidad de representar un constructo ideológico, se compone (como el caso de la portada de la revista Estampa de 15 de abril de 1933) o bien se acude a fotografías poco publicadas de personajes conocidos como Alfred Dreyfus con gafas oscuras. Este mensaje tiene una gran capacidad de adaptación, pues los judíos son representados como conspiradores comunistas, bolcheviques o masones, pero también capitalistas. Icónicamente los dos personajes más repetidos y que mejor asumen ese papel de conspiradores, a la vez que de judios ocultos (que no pueden ser retratados como judíos), son León Blum y Troski. Coincidente con esta visión del judío, es una imagen a menudo repetida, fundamentalmente en las informaciones de la década de 1940 coincidiendo con las noticias del protectorado británico de Palestina y el movimiento sionista, la de representar a los judíos como elementos terroristas que conspiran contra el orden establecido.

Una tercera imagen es la de presentar a los judíos como personas errantes: las fotografías se centran en captar momentos en los que los judíos viajan o se refugian de persecuciones o matanzas.. Esta imagen del judío errante está relacionada con la acusación de deicidio. En la memoria cultural este mito tiene una amplia pervivencia: los judíos son perseguidos porque sobre ellos pesa el castigo y por tanto sus rostros de dolor no provienen de la persecución, sino de su supuesta culpa. Esto lleva a que incluso las informaciones de los refugiados del nazismo sean considerados como judíos errantes y no como refugiados políticos. Junto a esta imagen estereotipada, los no judíos europeos se fotografían como salvadores que le brindan protección. 
Una tercera imagen muy destacada es la del judío como persona ligada a la usura. En este caso se busca la fotografía del judío en su comercio, en el mercado, en el banco o simplemente haciendo negocios. Es recurrente la utilización de fotografias que son tituladas como mercado judío, o las referencias a familias de banqueros como los Rotschild donde se destaca su condición de judío.

Por último, otro grupo de fotografías que coinciden en todos las revistas analizadas es la de mostrar los espacios de vida de manera estereotipada. Mientras que en las juderías del Magreb o de los países del este de Europa, se busca incorporar al espacio urbano al tipo judío reconocible, en las centroeuropeas o las nuevas ciudades del Protectorado de Palestina (excepto el caso de Jerusalén) esos espacios urbanos están exentos de figuras humanas o se sitúan en la lejanía. La razón de esto último está en que al no responder los habitantes judíos al tipo judío reconocible se obvia su presencia. Un caso particular es el de las antiguas juderías españolas de la península: son imágenes urbanas sin presencia humana que evocan una ausencia. Son espacios resimbolizados por la fotografía que llaman a leyendas, a visiones pintorescas y casticistas sin faltar elementos que empiezan a llamar a un incipiente turismo.

\section{Conclusiones}

Concluimos que la fotografía es un mecanismo de creación de alteridad en estrecha relación con la memoria cultural y su imaginario. El fotógrafo busca que lo que se represente sea reconocible por el lector y para ello acude a unos estereotipos que están modelados por la ideología y los discursos hegemónicos que son los que forman la memoria cultural y social.

Los constructos del imaginario responden una urdidumbre ideológica-conceptual que cada sistema cultural determina (Grau Rebollo, 2002; 39) y que el fotógrafo no copia, sino que recrea (Buxó, 1999). Así, cuando miramos una fotografía que nos muestra a grupos sociales, debemos tener presente nuestra concepción del mundo, nuestra mirada y los mecanismos de codificación con los que creamos a ese Otro para que se reconocible.

La fotografía, y con más en concreto la fotografía de prensa, es un mecanismos de transmisión e incluso de creación de estereotipos y de alteridades. Para el estereotipo es un elemento crucial su difusión y son los medios de información de actualidad, los referentes de la mayor parte de la sociedad, los que revisan, sostiene y conducen los estereotipos (González Galiana, 1999;103).

\section{Referencias bibliográficas}

AGUIRRE, Ángel (coord., 1997): Introducción a la Antropología. Barcelona, Bárdenas, págs. 141-142.

BAER, Alejandro y ZUKIERMAN, Federico (2004): "Nuevo antisemitismo, viejos estigmas". Raíces, $\mathrm{n}^{\circ}$ 58, pp. 25-38.

BAER, Alejandro (2005): El testimonio audiovisual. Imagen y memoria del Holocausto. Madrid, Centro de Investigaciones Sociológicas.

BARTHES, Roland. (1986): Lo obvio y lo obtuso: imágenes, gestos, voces. Barcelona, Paidós. 
BUXÓ, Ma . Jesús (1999): De la investigación audiovisual, Barcelona, Proyecto A.

CARO BAROJA, Julio (1978): Los judios en la España Moderna y Contemporánea. Madrid, Istmo. $3 \mathrm{~V}$.

CLIMO, Jacob y CATELL, Maria (eds., 2002): Social Memory and History. Anthropological Perspectives. Walnut Crrek, Altamira Press.

ESPINOSA-RAMÍREZ, Antonio B. (2013): “Los judíos marroquíes vistos a través del periódico africanista 'La Estrella de Occidente" Miscelánea de Estudios Árabes y hebraicos. Sección hebreo, 63:41-55.

FRESSARD, Olivier (2006): "El imaginario social o la potencia de inventar de los pueblos" Trasversales, $\mathrm{n}^{\circ} 2$, Primavera. www.trasversales.net/+2alfre.htm [Consultado en línea el 1 de abril de 2014].

GILMAN, Sander (1991): The Jewish body. New York, London, Routledge.

GAONA PISONERO, Carmen y TORREGROSA CARMONA, Juan Francisco (2013): "La identificación del imaginario colectivo. El caso de los alumnos de Comunicación en el marco del EEES". Estudios sobre el mensaje periodístico, Vol. 19, núm. especial marzo, pp. 197-205. Madrid, Servicio de Publicaciones de la Universidad Complutense.

GONZÁLEZ GALIANA, Rafael (1999): "La construcción de estereotipos andaluces por los medios" Comunicar, 12 marzo, pp. 101-106.

GONZÁLEZ REYERO, Susana (2003): "Fijar un estereotipo: la fotografía y la nueva visión de la cultura ibérica (1898-1936). Segundas Jornadas Imagen, Cultura y Tecnología. Madrid, Universidad Carlos III. pp. 265-288.

GRAU REBOLLO, Jorge (2002): Antropología audiovisual. Barcelona, Bellaterra.

HALBWACS, Maurice (2004): La memoria colectiva. Zaragoza, Prensas Universitarias de Zaragoza.

IRALA HORTAL, Pilar (2011): "Retórica fotográfica y periodismo literario". Estudios sobre el mensaje periodístico, Vol. 17, $\mathrm{n}^{\mathrm{o}}$ 1, pp. 57-65. Madrid, Servicio de Publicaciones de la Universidad Complutense.

MATAS MORELL, Arnau (2010): "Los lugares de la memoria. Una mirada frenológica a la noción filosófica de memoria". Revista de Paz y Conflictos. $\mathrm{N}^{\mathrm{o}} 3$, págs. 76-92.

MOLINA FIGUERAS, Joan (2007): La imagen y su contenido. Perfiles de la iconografía antijudía en la España Medieval. Girona a l'abast XII.

MORALES LEZCANO, Víctor (1988): Africanismo y orientalismo español, Madrid, UNED

RAPOSO QUINTANA, Gabriela (2009): "Narrativas de la imagen: memoria, relato y fotografía". Revista Chilena de Antropología Visual, 13, junio, pp. 79-103.

SEMPRÚN, Jorge (1986): "Prefacio" En POLIAKOV, León (1986): Historia del antisemitismo. La Europa suicida, 1870-1933. Barcelona, Mario Muchnik. 